\title{
An Interdependent Multi-Layer Model: Resilience of International Networks
}

\author{
Simone Caschili • Francesca Romana Medda • \\ Alan Wilson
}

Published online: 22 March 2015

(C) The Author(s) 2015. This article is published with open access at Springerlink.com

\begin{abstract}
Trade flows are characterised by interdependent economic networks such as the global supply chain, international bilateral agreements, trans-national credit, and foreign direct investments, as well as non-economic components (i.e. infrastructures, cultural ties and spatial barriers). We construct an Interdependent Multi-layer Model (IMM), which is rooted in the theoretical concept of spatial interaction, in order to identify the links within these networks and trace their impacts on trade flows. In our aim to investigate horizontal and vertical interdependency among networks we calibrate the interaction model (IMM) for a set of 40 countries, and thereafter examine the influence of shocks such as economic downturns upon the interdependent networks, which in our model are represented as economic, socio-cultural and physical layers. Most importantly, the model allows us to understand the propagation of cascading effects (both positive and negative) at national and global scales.
\end{abstract}

Keywords Trade $\cdot$ Multi-layer network $\cdot$ Complexity $\cdot$ Spatial interaction models

\section{Introduction}

Disruptions to socio-cultural, economic and ICT systems, among other areas, can have direct consequences on our daily lives. Natural disasters such as Hurricane Katrina and the 2011 earthquake in Japan underline how our cities, regions and nations are composed of complex interdependent systems (Akhtar and Santos 2013; Burns and Slovic 2012; Matsziw et al. 2009; Levin et al.

S. Caschili $(\bowtie) \cdot$ F. R. Medda

UCL QASER Lab, University College London, Faculty of Engineering, Chadwick Building, Gower

Street, London WC1E 6BT, UK

e-mail: simon.caschili@gmail.com

S. Caschili • A. Wilson

Centre for Advanced Spatial Analysis, University College London, 90 Tottenham Court Road,

London W1T 4TJ, UK 
1998). As systems become more interconnected their interdependence also grows, therefore as a consequence we ask, is it possible to evaluate the ability of systems to recover or renew after a shock? And if so, what can we learn about their resilience capacity in order to design better and more reliable economic systems?

Recent advances in complexity science have heightened the demand for investigations into economic systems and their resilience to disruptive events (Marincioni et al. 2013; Liu et al. 2007). In this sense, complexity science provides new insights into the study of economic processes that are complex, self-organising and adaptive, with specific and with interconnected components or sectors, at both national and international scale (Holt et al. 2011; Markose 2005; Rosser 1999). For example, global supply chains are characterised by interrelated organisations, resources and processes that create and deliver products and services to consumers in countries around the world. The activity of buying a product or using a service then impacts not only on the national economy where the purchase happens but also affects several other international economies (Bade and Parkin 2007; Shahabi et al. 2013). Global supply chains are grounded on the notion that each firm contributing to the chain can provide a service or good at a price below the domestic price of final consumption (Teng and Jaramillo 2005). Such an economic system is likely to be profitable when a particular country has an economic advantage due to its availability of specific natural resources, a cheap labour force or a specialised technology (Garelli 2003). But this is not enough. An efficient distribution chain must be structured so that equal relevance is given to the hard infrastructures (i.e. ports, railways, roads, etc.) as well as to the soft infrastructures (how infrastructures are operated) of the chain, which ultimately determines the competitive advantage of low transport costs (Gunasekaran et al. 2001). Finally, as global trade increases, firms enlist trusted partners when operating within the international trading environment. International economic agreements have in fact enabled increased volumes of capital, goods and services transacted across traditional state borders, thereby raising direct foreign investments and the level of economic engagement across countries (Büthe and Milner 2008).

Within this framework we carry out a quantitative analysis based on the equilibrium interaction approach in our study on international trade. We have constructed an Interdependent Multi-layer Model (IMM) to investigate horizontal and vertical interdependence among networks within the international trade system. The IMM model allows us to estimate bilateral trade flow between countries (imports and exports), and in so doing detect the effect of shocks in the system, identify the countries that allow for the spread of 'effects,' and analyse the propagation of impacts on trade.

The paper is set out as follows. In Section 2 we present a discussion on network resilience and present the main concepts underlying the construction of the Multi-layer model. In Sections 3 through 5 we examine the assumptions, the layers and the algorithm comprising the model. In Section 6 our data set and calibration process is presented, and in Sections 7 and 8 we clarify the results of the model at the steady state and after the introduction of system shocks. Section 9 concludes with comments on future extensions of the present work. 


\section{Network Resilience and Interdependence in Multi-Layer Models: Vertical Integration}

Networks are ubiquitous across societies and economies in the form of physical networks such as transportation, communication and utility services, and also as intangible economic, financial and social networks (Caschili et al. 2014; Clauset et al. 2008; Newman 2003; Strogatz 2001). Whatever their nature, as technology progresses we are becoming more dependent on networks and networks are simultaneously becoming more interdependent (Burger et al. 2014; Rinaldi et al. 2001). The organisation and growth of a network determines its success or failure and consequently influences other interdependent networks (Castet and Saleh 2013). For instance, over the last 15 years we have witnessed the exponential growth of the World Wide Web; this virtual network has transformed numerous other networks, including transportation, commerce and supply chains. In the case of retail business, the introduction of ecommerce as an alternative to traditional commerce has increased competitiveness, provided countless specialised services, and opened access to much wider markets (Harvie 2004).

In this study we focus on scrutinising the interconnectivity among various systems (economic, socio-political and infrastructural networks) and understanding the transmitted effects among those layer-systems (Ducruet and Beauguitte 2013). In this sense we can use the concept of resilience in order to describe the capacity of a hierarchical economic system (composed of several sub systems), to recover after being subject to a variety of challenges (shocks, disruptions, attacks, etc.) which move the system from its equilibrium. According to the notion of 'engineering resilience' (Pimm 1984) the faster a system returns to the equilibrium the higher its resilience. In 'ecological resilience' (Holling 1973) resilience is seen as the speed at which a system is able to absorb a shock by transitioning between (new) equilibria. Focusing on economics systems, scholars have coned various definitions of resilience (Duval et al. 2007; Rose 2007; Hill et al. 2008; Martin 2012) connected to both engineering and ecological resilience (Reggiani et al. 2002). Our research question follows the ecological resilience literature (i.e., is it possible to evaluate the ability of systems to recover or renew after a shock) as we are interested in exploring how the systems evolves through new possible equilibria created by the interactions between and within the layers of the system (modelled as a hierarchical structure).

Let us conceptualise the interdependence among networks. When we consider a high level network such as one carrying trade flows, we can observe how it is underpinned by other networks - see the example in Fig. 1.

In Fig. 1(a) trade is depicted in yellow which is supported by migration, membership in alliances such as the EU, and (soft and hard) infrastructures. Whereas in Fig. 1(b) different kinds of noteworthy events are shown which have strong impacts on trade: financial failure, migration, illicit trade, and cyber-attacks.

As we notice in Fig. 2, the 'layers' are now represented in functional relationships in which an upper layer is a dependent variable and the next layer is the set of associated independent variables. Any of the latter can in turn be seen as a dependent variable with its own set of independent variables-hence we have multi-layering. Our next step is to develop this argument explicitly through the use of the relationships shown in Fig. 1. By using an aggregate 
(a)

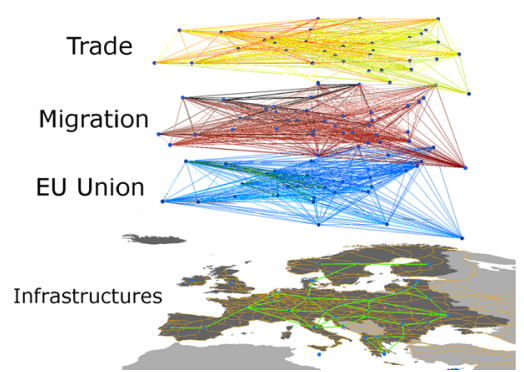

(b)

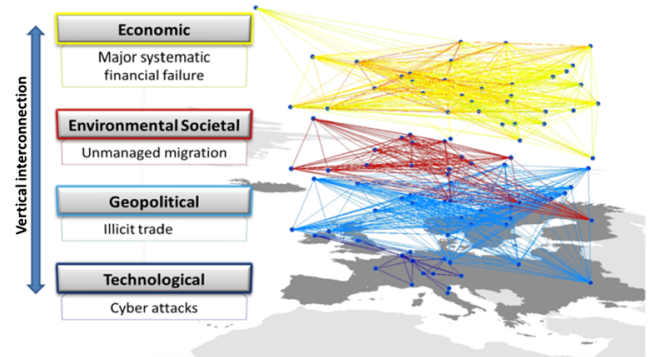

Fig. 1 A Multi-layer network's functional dependencies (a), 'events' (b)

picture of the system under consideration we are able to demonstrate the idea more easily.

These are all potentially interactive layers. Consider for example as layer the generalised transport cost, which represents the network of multi-lateral resistance to the movement of goods between countries (Aashtiani and Magnanti 1981). The physical layer not only representationally necessitates the transport cost from country $i$ to country $j$ but it also carries information about the underlying physical infrastructure (i.e. road, rail and air networks). A disruption in the physical infrastructure (due to disruptive events such as earthquake, hurricane, tsunami, etc.) generates impacts on transport costs. After an extreme event companies are compelled to re-route their supply chains, resulting in added days and higher logistics costs (Tang 2006; O'Kelly 2010). More specifically, if we treat transport cost as a network of relationships between supply and demand, we can evaluate the effects generated on bilateral trade flows. The same idea of network of relationships can be applied to other layers, including economic agreements, financial relationships and cultural ties. Furthermore, the hierarchical relational model described for the trade layer can be replicated for other variables and leads to a nested hierarchical system composed of multiple levels and multiple layers. We represent this idea in Fig. 3.

In this study we extend the concept of economic resilience to the case of nested hierarchical multi-layer networks. Interdependence between networks consists in transferring flows and information across the system. But the failure or reduced capacity of one of the networks' components could dramatically change the balance of flows.

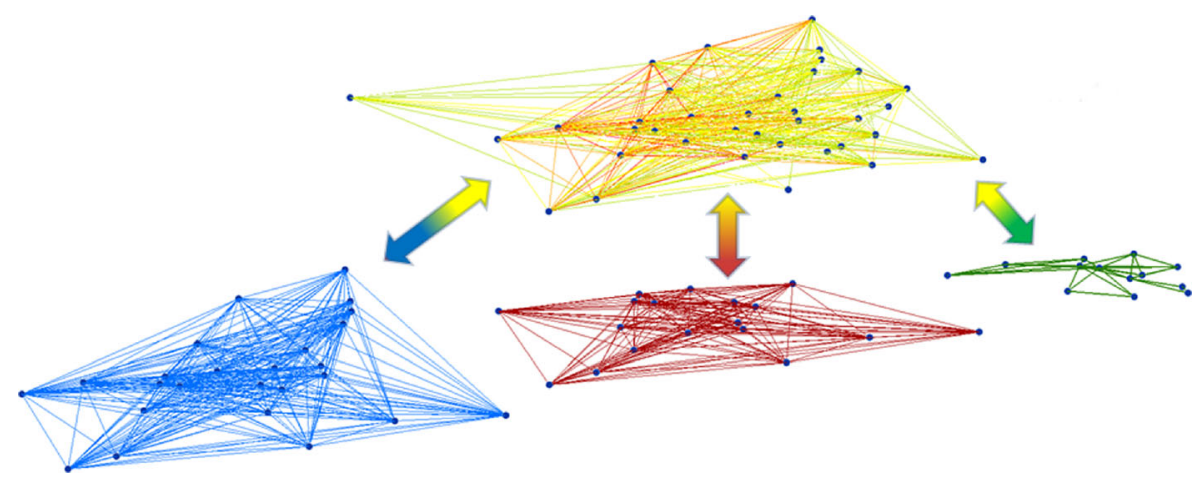

Fig. 2 Functional relationship between networks 


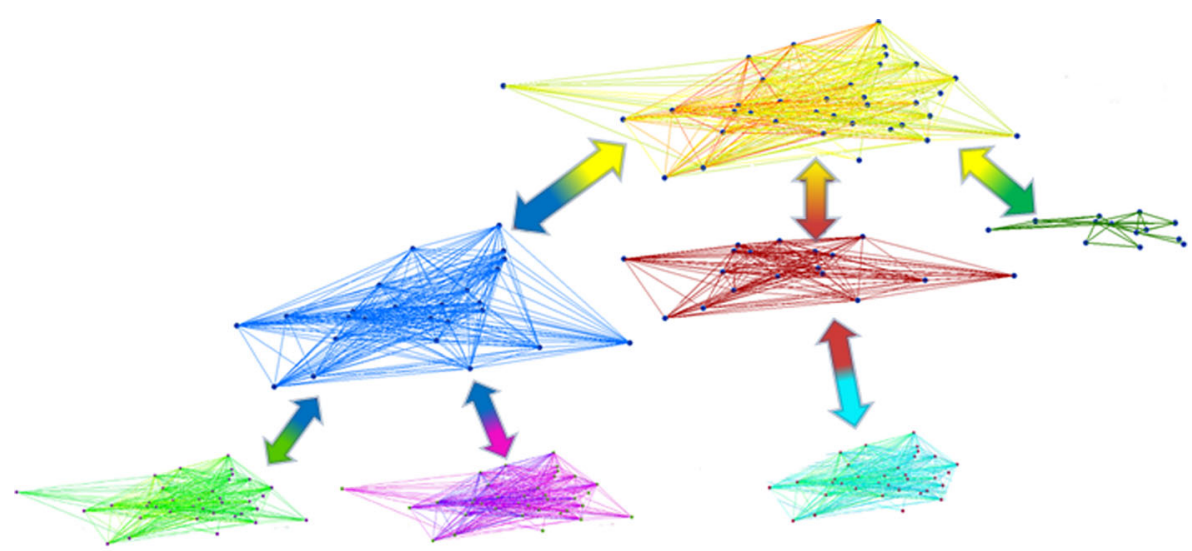

Fig. 3 A nested hierarchical multi-layer network

These events could bring the system to new equilibria which could eventually trigger cascading events. In this sense a number of scholars have started to recognise the importance in accounting for the interdependences between layers to evaluate the resilience of a multi-layer system (see inter alia, Buldyrev et al. 2010; Parshani et al. 2010; Gao et al. 2011).

In the next section we will build the model and calibrate it for the steady state in order to test the impact of the possible risks/hazards as shown in Fig. 1b: systematic financial failure, unmanaged migration, illicit trade flow, and cyber-attacks or piracy.

\section{Model Layers}

Various studies have long noted tangible and intangible factors that affect international trade (Linders et al. 2005; Anderson and Van Wincoop 2004; Deardorff 1998). Here we consider factors as interrelating layers in accordance with the vertical scheme discussed in Section 2. We have grouped factors in economic, socio-cultural and physical layers. In the remainder of this section we provide a description of each layer and the models we have constructed for the estimation process.

\subsection{Economic Layer}

International trade is shaped by the factor productivities of every country, and certainly from this perspective trade leads to specialisation and interdependence within different national economies. However, as Helpman observes: "exports are not valuable per se, but rather via the quid pro quo of the exchange in which they pay for imports" (2011); in other words, bilateral trade is affected by changes in the levels of various economic elements such as exchange rates (Bergstrand 1985), border tariffs (Yue et al. 2006) and national wealth (Hufbauer 1970). In our model we assume that these economic elements not only interact with the other non-economic considered layers but also in turn they have the capacity to shape, re-adapt and create the overall trade pattern. The two relationships are therefore mutual. 


\subsubsection{Bilateral Trade}

We use a spatial interaction model framework (Wilson 1967, 1970) in order to describe the bilateral interactive nature of trade. Let $T_{i j}$ be a measure of the trade flow from country i to country $\mathrm{j}$ measured in monetary value (USD). To guarantee the consistency of our model, we impose constraints to ensure that exports (E) and imports (I) are equal to the sum of outward and inward flows of each country:

$$
\begin{aligned}
& \sum_{j} T_{i j}=E_{i} \\
& \sum_{i} T_{i j}=I_{j}
\end{aligned}
$$

Following a classic notation for spatial interaction models, we can write the trade between two countries $i$ and $j$, as follows:

$$
T_{i j}=A_{i} B_{j} E_{i} I_{j} f\left(\beta, \operatorname{cost}_{i j}\right)
$$

where $f\left(\beta, \cos t_{i j}\right)$ is a general measure of impedance between $i$ and $j$ as a function of the unit cost of shipping, cost $_{\mathrm{ij}}$ is measured in monetary value per unit of volume per unit of distance. $\mathrm{A}_{\mathrm{i}}$ and $B_{j}$ are balancing factors which can be written as:

$$
\begin{aligned}
A_{i} & =\frac{1}{\sum_{j} B_{j} I_{j} f\left(\beta, \text { cost }_{i j}\right)} \\
B_{j} & =\frac{1}{\sum_{i} A_{i} E_{i} f\left(\beta, \text { cost }_{i j}\right)}
\end{aligned}
$$

We estimate the model in (1) from data, using the Correlates of War Project's Trade Data (Barbieri et al. 2009). The data set includes annual dyadic and national trade figures. Bilateral trade is obtained from the International Monetary Fund's Direction of Trade Statistics (2012) (see Section 5 for details).

We develop the multi-layer nested framework introduced in Section 2 for bilateral trade by considering physical and cultural layers. We account for the cultural factors as networks, which we mathematically represent as matrices: exchange rate $\left(\mathrm{ER}_{\mathrm{ij}}\right)$, a variable identifying whether two countries share a border $\left(\mathrm{CB}_{\mathrm{ij}}\right)$, and cultural ties $\left(\mathrm{CL}_{\mathrm{ij}}\right)$. The spatial interaction model of Eq. (3) can now be written as:

$$
T_{i j}=A_{i} B_{j} E_{i} I_{j} \mathrm{f}\left(\beta, \operatorname{cost}_{\mathrm{ij}}\right) E R_{i j} C B_{i j} C L_{i j}
$$

where balancing factors are expressed as:

$$
\begin{aligned}
A_{i} & =\frac{1}{\sum_{j} B_{j} I_{j} f\left(\beta, \operatorname{cost}_{i j}\right) E R_{i j} C B_{i j} C L_{i j}} \\
B_{j} & =\frac{1}{\sum_{i} A_{i} E_{i} f\left(\beta, \operatorname{cost}_{i j}\right) E R_{i j} C B_{i j} C L_{i j}}
\end{aligned}
$$


When we examine the schema presented in Figs. 2 and 3, the matrices which are components of Eq. (6): $\left\{\mathrm{T}_{\mathrm{ij}}\right\},\left\{\operatorname{cost}_{\mathrm{ij}}\right\},\left\{\mathrm{ER}_{\mathrm{ij}}\right\},\left\{\mathrm{CB}_{\mathrm{ij}}\right\}$ and $\left\{\mathrm{CL}_{\mathrm{ij}}\right\}$ can now all be regarded as networks, or layers, of the Interdependent Multi-layer Model.

\subsubsection{Economic Scale of a Country}

For economic scale of a country we assume here that countries with large net exports of products have equally large domestic production and domestic absorption, consisting of consumption, investment and government spending (Kuznets 1946). We represent this scale by the Gross Domestic Product (GDP). We also consider the GDP per capita (GDPpc) which is often used to appraise the personal wealth of a nation (OECD 2009). GDP is calculated using the expenditure method as follows:

$$
\mathrm{GDP}_{\mathrm{i}}=\mathrm{C}_{\mathrm{i}}+\mathrm{INV}_{\mathrm{i}}+\mathrm{G}_{\mathrm{i}}+\mathrm{E}_{\mathrm{i}}-\mathrm{I}_{\mathrm{i}}
$$

where $C_{i}$ is spending on personal consumption (durable goods, non-durable goods and services), $\mathrm{INV}_{\mathrm{i}}$ gross private domestic investment (residential, non-residential and change in business), $G_{i}$ is the total government spending, and $E_{i}$ and $I_{i}$ are, respectively, exports and imports. We divide GDP into the national component (NC) and net trade component (NetT):

$$
\begin{gathered}
G D P_{i}=N C_{i}+N e t T_{i} \\
N C_{i}=\mathrm{C}_{\mathrm{i}}+\mathrm{INV}_{\mathrm{i}}+\mathrm{G}_{\mathrm{i}} \\
N e t T_{i}=\mathrm{E}_{\mathrm{i}}-\mathrm{I}_{\mathrm{i}}
\end{gathered}
$$

We estimate $N e t T_{i}$ at each time $t$ by calculating trade flows through Eq. (6). We estimate the national component of GDP $\left(\mathrm{NC}_{\mathrm{i}}\right)$ proportional to the population of the country i:

$$
N C_{i}(t)=\alpha_{i}(t) * \operatorname{Pop}_{i}(t)
$$

$\alpha_{i}(t)$ is a coefficient which considers the national consumption, investments and government spending per capita. We estimate the value of $\alpha_{i}(t)$ at each time $t$ as follows:

$$
\alpha_{i}(t)=\alpha_{i}(t-1) *\left(1+\delta_{i}(t)\right)
$$

$\delta_{i}(t)$ is a stochastic coefficient which is proportional to the annual variation of GDP per capita and economic growth rate of country $i$.

\subsubsection{Exchange Rate}

At present there is much interest in determining the effect of currency on trade. Indeed, one important reason for forming a currency union is the promotion of trade within the union. With the exception of currency unions, the exchange rate between two countries might favour or impede bilateral trade. We assume that the higher the ratio between 
exporter country $i$ and importer country $j$, the higher the trade between the two countries. We construct the exchange rate layer where a link between two countries $i$ and $\mathrm{j}$ is equal to the ratio between the two countries' exchange rate (ER) (local currency relative to the U.S. dollar):

$$
E R_{i j}=\frac{E R_{i}}{E R_{j}}
$$

\subsubsection{Transport Cost}

Transport cost is one of the major variables affecting bilateral trade. To some extent, import choices are made to minimise transport costs (Hummels 1999). The literature on international trade has shown that transport costs are mainly influenced by freight rates, economies of scale, infrastructure quality, and importer/exporter location (Immaculada and Celestino 2005). From the shipper's point of view, there are three categories of costs that determine freight rates: capital costs (fleet acquisition), direct fixed costs (insurance, fleet maintenance, personnel costs, etc.) and variable costs (combustible costs, port costs and type of product traded). Rauch (1999) has shown that differentiated products (i.e. products with a distinct identity and over which the manufacturer has some control regarding price) have higher freight costs due to the search cost buyersupplier. Against this background, gravity models have been extensively applied to represent bilateral trade (Tinbergen 1962; Pullianen 1963; Linneman 1966; Bergstrand 1985; Anderson and Van Wincoop 2004; Baldwin and Taglioni 2006) and geographical distance has been often used to approximate transport costs. Results of these models have proved that spatial distance is a good proxy for transport costs when trade is studied at the aggregated level, while it is not clear whether this good performance of the proxy remains if trade is analysed at the disaggregated level (Hummels 1999; Immaculada and Celestino 2005). In this study we consider two types of transport costs: geographical distance and a generalised version of transport cost, $T C_{i j}$, between location $i$ and $j$ based on the work of Limao and Venables (2001) as follows:

$$
T C_{i j}=f\left(d_{i j}, C B_{i j}, I s l_{i}, I s l_{j}, Y_{i}, Y_{j}, \operatorname{Inf} f_{i}, \operatorname{Inf} f_{j}\right)
$$

where $\mathrm{d}_{\mathrm{ij}}$ is travel distance between country $i$ and $j, \mathrm{CB}_{\mathrm{ij}}$ takes into consideration common borders between country $i$ and $j$; Isl accounts for the insularity of a country, $\mathrm{Y}_{\mathrm{i}}$ is per capita income, and Infi is an indicator of the quality of the infrastructure and the logistics of a country. Because of lack of information we have introduced some simplifications in Eq. (16): the GDP per capita is used as a proxy of the per capita income, and we do not consider insularity in determining transport costs.

\subsection{Social and Cultural Layer (Socio-Cultural)}

Population and measures of 'cultural distance' have also been considered as determinants of international trade (Glick and Rose 2002). In fact, population increases trade and the level of specialisation (Matyas 1997). Population may have a positive impact on trade flows in the short run, since it may increase the number of the labour force, the level of specialisation and more products to export as a result. However, in the long run 
higher population has a tendency to decrease income per capita, making every individual poorer, and therefore it may cause production and exports to decrease. In addition to that, lower income per capita tends to decrease the demand for imports as well.

\subsubsection{Population}

We estimate the variation of population at each time $t$ as the variation due to the internal demographic changes (birth and death rates) and the net migration in the country:

$$
\operatorname{Pop}_{i}(t)=\operatorname{Pop}_{i}(t-1)+\text { births }_{i}(t)-\text { deaths }_{i}(t)+\operatorname{in}_{\text {migratio }} n_{i}(t)-\text { out }_{\text {migratio }} n_{i}(t)
$$

In order to estimate internal demographic change, we consider an average constant value of births and deaths at each time $t$ for each country.

We estimate migration flows between countries as a function of GDPpc of the two countries, the population in the two countries, physical distance, and cultural distance:

$$
M_{i j}=M_{i j}\left(G D P p c_{i}, G D P p c_{j}, \operatorname{Pop}_{i}, \operatorname{Pop}_{j}, d_{i j}, C L_{i j}\right)
$$

We expect that the higher the difference in GDP per capita of the two countries, the higher the migration will be from the country with lowest GDP per capita to the country with higher GDP per capita. Physical distance should negatively influence migration while a cultural linkage should increase migration. Total immigration and emigration of each country are next calculated as follows:

$$
\begin{aligned}
\text { in-migration }_{i} & =\sum_{j} M_{i j} \\
\text { out-_migration }_{j} & =\sum_{i} M_{i j}
\end{aligned}
$$

\subsubsection{Colonial Link}

We use the dummy variable $\mathrm{CL}_{\mathrm{ij}}$ equal to 1 when there is a colonial history between country $i$ and $j, 0$ otherwise. The information is obtained from the CEPII data set (Head et al. 2010).

\subsection{Physical Layer}

Infrastructures are the means through which goods are traded and they may have a large effect on trade costs. Travel distance is the first determinant which defines direct monetary outlays for trade (see Section 3.1, Transport Costs).

\subsubsection{Common Borders}

Many studies have confirmed that the influence of distance on trade is non-linear, with trade between bordering countries being significantly greater than countries that are positioned at similar distances, but do not share a border (McCallum 1995). We take 
into consideration this determinant by generating a layer in which countries sharing a border are interconnected. We construct the dummy variable $C B_{i j}$ equal to 2 when country $i$ and $j$ share a border, 1 otherwise.

\subsubsection{Distance}

Transport distance is one of the major variables influencing transport cost because distance represents an impediment to trade. The greater the distance between two countries, the higher is the cost to transport goods, thereby reducing the gains from trade. We approximate the average transport distance between countries by applying the Euclidian distance between national capitals, $d_{i j}$.

\subsubsection{Infrastructure Quality}

In Section 3.1, Transport Cost, we have discussed how the quality of infrastructures and the cost and quality of related services is connected to the transport costs. All these factors also influence delivery time. In fact, poor quality infrastructure increases the uncertainty of delivery, which is associated with a higher risk of damage, and therefore with higher losses and insurance costs. The quality of infrastructure thus largely determines the time required to get products to market and the reliability of delivery. We use the World Bank's Logistic Performance Index to estimate the quality of trade and transport-related infrastructure.

\section{The Workings of the Model}

The IMM model is based on the following assumptions:

- Immigrant and native are considered as a homogeneous class of workers;

- We assume flexibility in the labour market, which is the flexibility of wages to adjust demand and supply and the capacity to differentiate wages for new labour outcomers in the market;

- Intensive margin increase through time (i.e., existing bilateral trading relationships increase through time);

- Labour-intensive goods (logistics, manufacturing, agriculture), i.e. the costs of labour make up a high percentage of total costs;

- Local externalities are constant.

We now show how these assumptions are used in the model.

The model is composed of the layers presented in Section 3 and grounded on the assumptions set out above. The IMM operates with a combination of sub-models which in sequence determine the variation of model parameters through time. The system dynamics are described in a sequence of steps. We begin with two assumptions:

- import, export, population, transport cost, exchange rate, spatial proximity, and cultural links are at their initial state; and 
- population changes according to death rate, birth rate and net migration of each country.

Given these assumptions, we work with the following algorithm whose structure is shown in Fig. 4.

1. Start from a fixed configuration on the IMM, nation-by-nation: population $\left(\operatorname{Pop}_{\mathrm{i}}(\mathrm{t})\right)$, GDP $\left(\operatorname{GDP}_{\mathrm{i}}(t)\right)$, transport costs $\left(\operatorname{Cost}_{\mathrm{ij}}(t)\right)$, and migration $\left(\mathrm{M}_{\mathrm{ij}}(t)\right)$, which are sufficient to calculate $\mathrm{T}_{\mathrm{ij}}(t)$, the trade. We call this configuration $\mathrm{C}(t)$ : the initial configuration of the system.

2. Disequilibrium in GDP per capita stimulates migration;

3. Migration, birth and death rates change the total population of each country;

4. The change in population generates a modification in the GDP and GDP per capita of each country (GDPpc $(t+1))$;

5. The change in the GDP per capita generates a modification in transport Costs $\left(\operatorname{Cost}_{\mathrm{ij}}(t+1)\right.$;

6. The change in the transport costs generates a modification in bilateral trade $\mathrm{T}_{\mathrm{ij}}(t+1)$;

7. The previous step modifies import, export of each country and thus the GDPs of both;

8. Return to Step 1.

In Fig. 4, each circle represents a sub model calibrated at the steady state and provides the forecasts for bilateral trade, GDP and Migration, as discussed in Section 3. We assume that each country behaves in the same way through time, and that no external events affect this configuration. In reality, as we know, internal national and external international events/shocks shape the overall trade pattern of a country. The effect of any shock at any point in time can be introduced into the model by

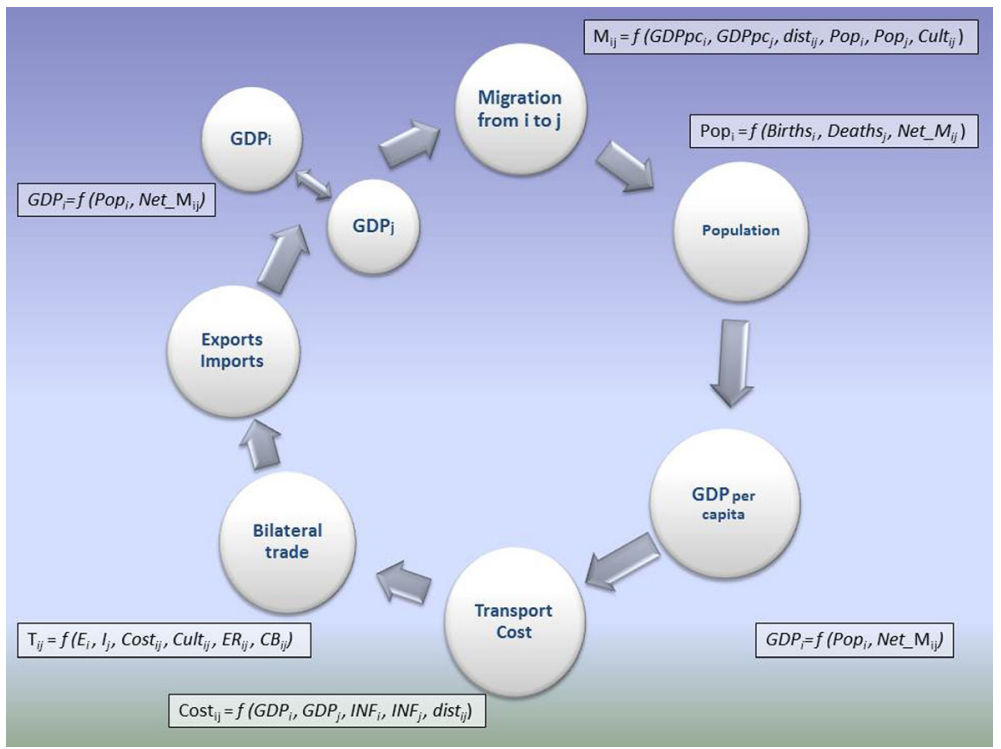

Fig. 4 Multi-layer interactive process 
introducing a change in one or more sub models for one or more countries. In this way we can estimate consequences and impacts of an event in the system. In Section 7 we test the IMM by simulating the overall effect generated in the system through the imposition of a shock, that is, we introduce a reduction of per capita consumption and investment in the USA and Germany.

\section{Model Calibration}

We have calibrated the IMM at the steady state using data collected from several sources for 40 countries (Tables 1 and 2). Data at the steady state are for the year 2000. To assure equilibrium in the model, we also introduce a virtual 'country' which accounts for the rest of the world (RoW).

Information on bilateral trade is derived from the Correlates of War Project's Trade, which uses information from the International Monetary Fund's Direction of Trade Statistics (Barbieri and Keshk 2012; Barbieri et al. 2009). Parts of the information of this study have been extracted from the on-line World Bank Data Catalog (http://data.worldbank.org/data-catalog), an open data set providing over 8,000 indicators and covering 214 countries from 1960 to 2011.

Information on migration has been derived from the Abel (2013) data set of estimates of bilateral migration flows between 191 countries. Finally, information on bilateral cultural and physical distance has been extrapolated from the GeoDist project (Mayer and Zignago 2011). The data set provides several geographical variables; in particular bilateral distances are measured using city level data. In the remainder of this section we will present the results for the calibration of the bilateral trade model (see Section 3.1) and the bilateral migration model (see Section 3.2).

The calibration of the bilateral trade model is based on: $(i)$ the impact of distance on trade and generalised trade costs (TC), (ii) the identification of the cost function to be included in the model, and (iii) the impact of economic, social and physical

Table 1 IMM variables and sources

\begin{tabular}{lll}
\hline Layer type & Variable & Source \\
\hline Economic & GDP & World Bank Data Catalog \\
& Trade & Barbieri and Keshk (2012) \\
& Exchange rate & World Bank Data Catalog \\
Social and cultural & Population & World Bank Data Catalog \\
& Birth, death rate & World Bank Data Catalog \\
& Per capita consumption & Own elaboration \\
& Migration & Abel et al. (2013) \\
& Cultural ties & Mayer and Zignago (2011) \\
& Distance & Mayer and Zignago (2011) \\
& Physical proximity & Mayer and Zignago (2011) \\
& Logistic performance index & World Bank Data Catalog \\
\hline
\end{tabular}

${ }^{\mathrm{a}}$ http://data.worldbank.org/data-catalog 
Table 2 List of countries

\begin{tabular}{ll}
\hline Geographic area & Countries \\
\hline Europe & Austria, Belgium, Bulgaria, Cyprus, Czech Republic, Denmark, Estonia, Finland, \\
& France, Germany, Greece, Hungary, Ireland, Italy, Latvia, Lithuania, \\
& Luxemburg, Malta, Netherlands, Poland, Portugal, Romania, Slovak Republic, \\
& Slovenia, Spain, Sweden, UK \\
Americas & Brazil, Canada, Mexico, USA \\
Asia and Pacific & China, India, Indonesia, Japan, Russia, South Korea, Australia, Taiwan, Turkey \\
\hline
\end{tabular}

determinants on trade. In relation to the first two, we consider the following decay functions:

$$
\begin{gathered}
f\left(\beta, d_{i j}\right)=\exp \left(\beta, d_{i j}\right) \\
f\left(\beta, d_{i j}\right)=d_{i j}^{\beta} \\
f\left(\beta, \mathrm{TC}_{i j}\right)=T_{i j}^{\beta}
\end{gathered}
$$

We have tested both exponential (Eq. 21) and power decay functions (Eq. 22) for geographical distance and generalised transport cost (Eq. 23). The power decay function provides us with better results than the exponential decay. This result is in line with the literature (see inter alia Wilson 1971) which has found that power decay functions provide better results for long travel distances. Empirical results demonstrate that our model fits the data better if we use geographical distance (Table 3) and this result is in line with other studies which have found geographical distance to provide better estimations of bilateral trade for aggregated products (Hummels 1999; Immaculada and Celestino 2005).

Finally, economic, cultural and physical layers were included in the model in order to evaluate if they improve its results (Eq. 6). We have verified that when we introduce Exchange Rate (ER), Colonial Link (CL) and Common Borders (CB) into the model, the statistics always improve. In the simulation presented in Sections 6 and 7, the trade

Table 3 Parameters estimates ( $\beta$ coefficient) and Pearson coefficient of correlation (in parenthesis)

\begin{tabular}{lcccccc}
\hline & & ER & CL & CB & ER, CL & ER, CL, CB \\
\hline Exponential $\left(\mathrm{d}_{\mathrm{ij}}\right)$ & 0.000233 & & & & & \\
& $(0.507)$ & & & & & \\
Power decay $\left(\mathrm{d}_{\mathrm{ij}}\right)$ & -1.54341 & -1.54354 & -1.48931 & -1.35623 & -1.48929 & -1.2755 \\
& $(0.905)$ & $(0.906)$ & $(0.909)$ & $(0.908)$ & $(0.909)$ & $(0.91)$ \\
Power decay (cost $\left.\mathrm{ij}_{\mathrm{ij}}\right)$ & -2.0096 & -2.0112 & -1.9843 & -2.02495 & -1.9856 & -1.99499 \\
& $(0.883)$ & $(0.884)$ & $(0.886)$ & $(0.877)$ & $(0.887)$ & $(0.889)$ \\
\hline
\end{tabular}


sub model is implemented by a power decay function with geographic distance and includes the layers ER, CL and CB.

We will next build and calibrate a bilateral migration flows' model using linear regression analysis in the canonical form:

$$
Y=\sum_{k} \beta_{k} X_{k}+\varepsilon
$$

In this calibration we introduce the following set of hypotheses:

- Migration between two countries is higher from a country with a low GDP per capita to a country with higher GDP per capita (H1).

- Migration flows are higher between countries with larger populations (H2).

- Distance influences migration negatively (H3).

- Common borders and cultural links increase the chances that one individual moves to another country (H4).

Standard linear regression (Eq. 24) estimates the dependent variable Y (migration between country $i$ and $j$ ) as a linear combination of the independent variables $\mathrm{X}$. The independent variables are: the ratio between GDP per capita of the two countries (H1), the total population in $i$ and $j(\mathrm{H} 2)$, the geographic distance $\mathrm{d}_{\mathrm{ij}}(\mathrm{H} 3)$, common border $\mathrm{CB}_{\mathrm{ij}}$ and Cultural Linkage $\mathrm{CL}_{\mathrm{ij}}(\mathrm{H} 4)$. We use a logarithm transformation in order to normalise the variables and a binary form for $\mathrm{CB}_{\mathrm{ij}}$ and $\mathrm{CL}_{\mathrm{ij}}$. Thus, Eq. 24 assumes the following form:

$$
\begin{aligned}
\log \left(M_{i j}\right)= & \beta_{G D P p c} \frac{\log \left(G D P p c_{j}\right)}{\log \left(G D P p c_{i}\right)}+\beta_{\text {pop }_{i}} \log \left(\text { Pop }_{i}\right)+\beta_{\text {pop }_{j}} \log \left(\operatorname{Pop}_{j}\right)+\beta_{d_{i j}} \log \left(d_{i j}\right) \\
& +\beta_{C B_{i j}} \log \left(C B_{i j}\right)+\beta_{C L_{i j}} \log \left(C L_{i j}\right)+\varepsilon
\end{aligned}
$$

We adjust Eq. 25 with a lognormal function in order to reduce the model's errors:

$$
M T_{i j}=M_{i j} * e^{\frac{\log \left(M_{i j}\right)}{M_{i j}}}
$$

All parameters $(\beta)$ are significant $(p$-value $\leq 0.001)$ and their signs are consistent with our hypotheses (Table 4). The model approximates the data quite well, having a very high $\mathrm{R}^{2}$ coefficient of determination $\left(R^{2}=0.908\right)$.

\section{Analysis of the Steady State}

After having collected data and calibrated the models, we can now focus on the objective of our study, which is to test the IMM in order to verify $(i)$ if the IMM mirrors real world scenarios, and (ii) to trace the effects generated by changes/shocks in the system.

In this part of the analysis we use a Monte Carlo approach for the simulation. The Monte Carlo strategy allows us to reduce the errors introduced in the model by the stochastic coefficient $\delta_{i}(t)$ of Eq. 14. In this way we can minimise the variance of our 
Table 4 Parameter estimates for linear regression on bilateral migration

\begin{tabular}{|c|c|c|c|c|c|}
\hline \multirow[t]{2}{*}{ Model } & \multicolumn{2}{|c|}{ Unstandardised coefficients } & \multirow{2}{*}{$\begin{array}{l}\text { Standardised } \\
\text { coefficients } \\
\text { Beta }\end{array}$} & \multirow[t]{2}{*}{$\mathrm{T}$} & \multirow[t]{2}{*}{ Sig. } \\
\hline & $\mathrm{B}$ & Std. Error & & & \\
\hline $\log \left(\mathrm{GDPpc}_{\mathrm{j}} / \mathrm{GDPpci}\right)$ & -8.242 & .482 & -1.311 & -17.092 & .000 \\
\hline $\log \left(\mathrm{Pop}_{\mathrm{i}}\right)$ & .557 & .026 & 1.511 & 21.168 & .000 \\
\hline $\log \left(\mathrm{Pop}_{\mathrm{j}}\right)$ & .695 & .033 & 1.876 & 20.786 & .000 \\
\hline $\log \left(d_{i j}\right)$ & -.904 & .058 & -1.169 & -15.711 & .000 \\
\hline $\mathrm{CL}_{\mathrm{ij}}$ & 1.420 & .259 & .050 & 5.491 & .000 \\
\hline
\end{tabular}

$R=0.953, R^{2}=0.908$

final result and thus also its statistical error. We have run the algorithm, described in Section 5, over 100 times for each scenario. Each final scenario is obtained by averaging the values of the 100 simulations in each time $t$.

In Fig. 5 we depict the four layers of the IMM: at the top from left to right are the trade and migration networks; on the bottom, cultural network (colonial links) and physical linkages (shared borders).

Table 5 summarises some statistical information for the trade and migration networks: average values of flows (w), clustering coefficient $\left(\mathrm{c}^{\mathrm{w}}\right.$ and $\left.\mathrm{c}\right)$, and sum of flows through a node (s). For the weighted clustering coefficient $\mathrm{c}^{\mathrm{w}}$ we use the equation proposed by Barrat et al. (2004), which measures the probability that two randomly selected nodes connected to a selected node are linked with each other where node cohesiveness is a function of the level of interaction between nodes. In our case, cohesiveness is heterogeneous across both networks: nodes are topologically highly connected (clustering coefficient c 0.88 and 0.96 , Table 5); when we examine the intensity of interaction among nodes, we can observe that structured clusters emerge. This is due to the fact that, although every country has at least one relation with all the other countries, trade and migration flows are heterogeneously distributed among nodes due to the several factors influencing these international relations (Sections 3.1 and 3.2).

Next in Fig. 6, we examine the traffic through each node $s$ by considering the directionality of flows. We plot the cumulative probability distributions of the sum of weighted in-connections $\mathrm{s}^{+}$(i.e. total Imports and total immigrants) and outconnections $\mathrm{s}^{-}$(i.e. Exports and total emigrants) per country. In the trade network the distributions of $\mathrm{s}^{+}$and $\mathrm{s}^{-}$are very similar and well approximated by power law decay (we fit the distribution with a Langmuir function, exponent $=1.17$ and $R^{2}=0.987$ ). The figure emerging from the migration network has similar distributions for immigration (s-) and emigration ( $\mathrm{s}^{+}$) per country. We fit the cumulative distributions with a Langmuir function, with exponent $0.98\left(R^{2}=0.996\right)$. Both networks are, however, characterised by pronounced disparities. Power law distributions, short distance between nodes and node clustering (Pastor-Satorras and Vespignani 2001) are common properties of social networks in which the level of activities of people is very heterogeneous, thus implying highly varying levels of involvement (Muchnik et al. 2013). In other words, a country interacts selectively with other countries. This is 

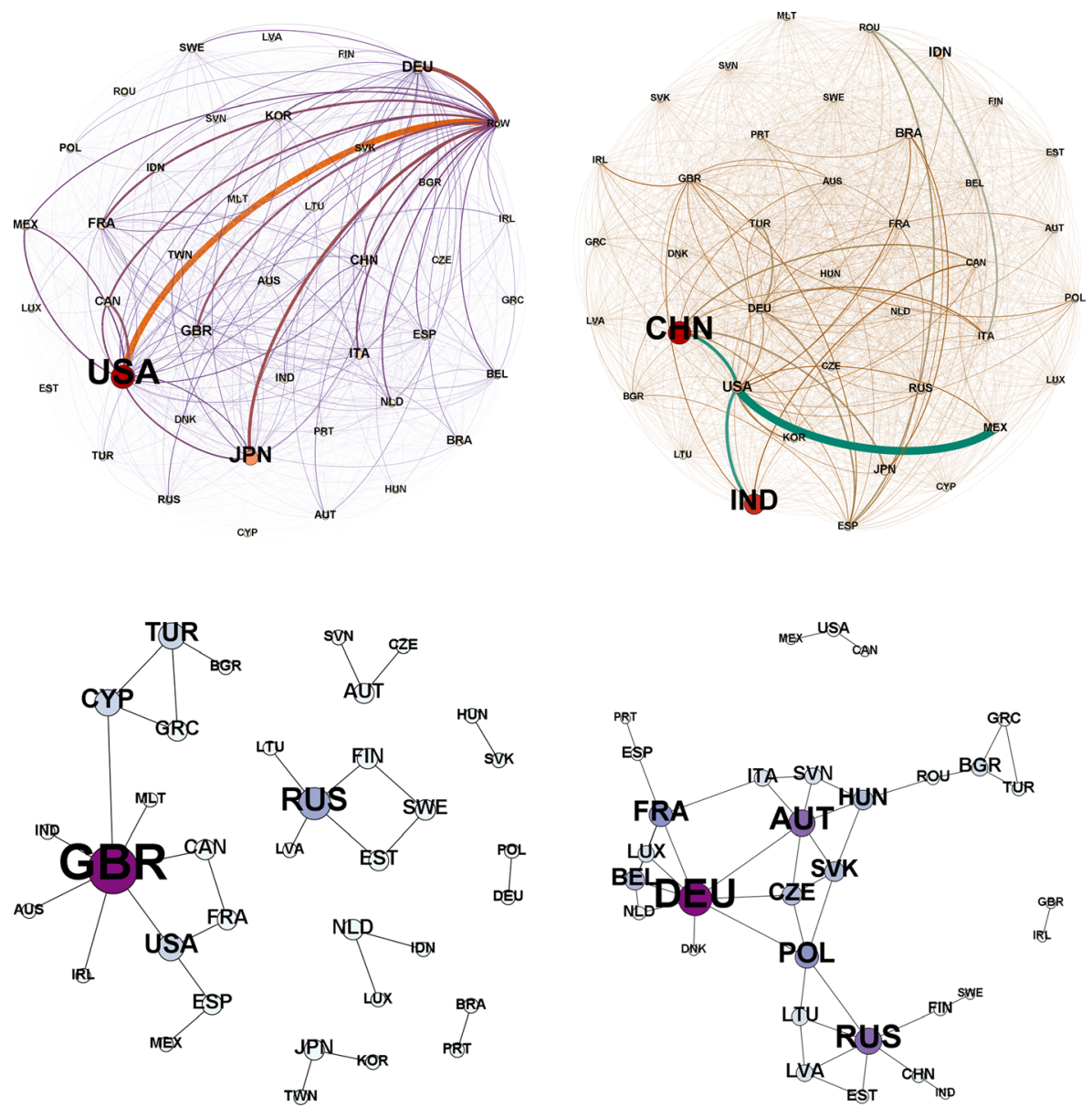

Fig. 5 Trade network (top left), migration network (top right), cultural network (bottom left) and network of common borders (bottom right). Link width is proportional to trade and migration flows, while node size and colour are proportional to national GDP in the trade network and to national population in the migration network. Node size and colour for colonial and common border networks are proportional to the number of connections

one of our main hypotheses tested in this work: we recognise that each country engages with other countries in different ways, due to its own spatial, economic and social conditions.

In the remainder of this section we present the results of the implementation of the algorithm described in Section 5. Each sub model has been calibrated with observed

Table 5 Main statistics of trade and migration networks: average link weight $<\mathrm{w}>$, weighted and topological clustering $<\mathrm{c}^{\mathrm{w}}>$ and $\mathrm{c}$, and average traffic intensity per node $<\mathrm{S}>$

\begin{tabular}{llllr}
\hline & $<\mathrm{w}>$ & $<\mathrm{c}^{\mathrm{w}}>$ & $\mathrm{C}$ & $<\mathrm{s}>$ \\
\hline Trade [\$US million] & 3,702 & 0.258 & 0.88 & 143,132 \\
Migration [People] & 6,298 & 0.315 & 0.96 & 199,167 \\
\hline
\end{tabular}



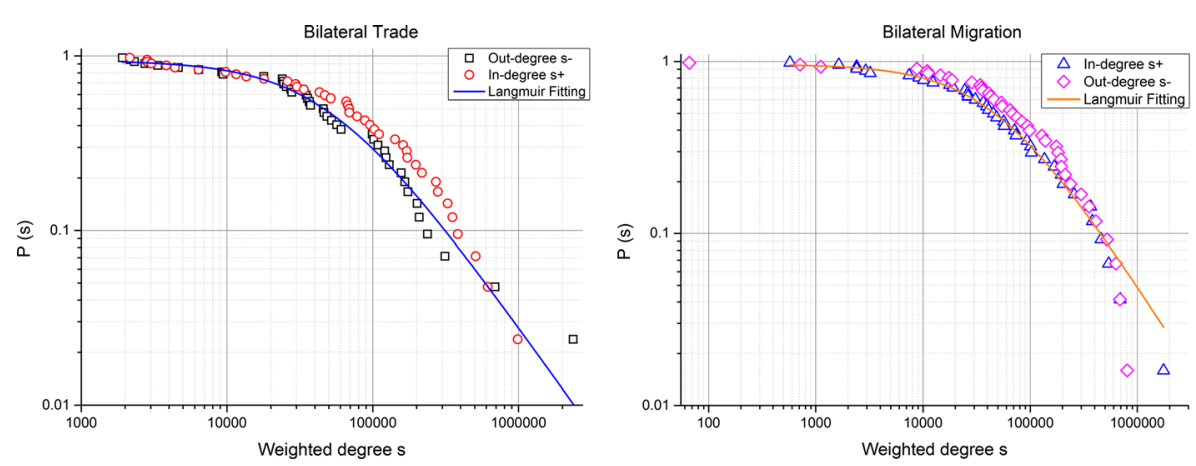

Fig. 6 Weighted in-degree $\mathrm{s}^{+}$and out-degree $\mathrm{s}^{-}$distributions for trade (left) and migration (right)

data from the year 2000. We use the GDP of each country in order to compare the IMM model's results with observed data from 2000 to 2011. As we have described in Section 3.1, GDP is a synthetic measure of the economic trend of a nation and is used to compare national economic performances. We use this indicator to appraise the effects generated by shocks on the Multi-layer model.

Results show that there is a strong evidence of correspondence between model outputs and the observed data for GDP. The observed visual correlation (Fig. 7) is also confirmed by the very high Pearson coefficient analysis $\left(R^{2}=0.988\right)$ in the period 2000 to 2007. The latter time span is a period of relative stability and growth for the majority of the countries in our sample, hence it is suitable for the validation of the IMM in the steady state We plot the model results below for three cases: major European economies (Fig. 7a and b), the Baltic States and Bulgaria (Fig. 7c and d) and the six major world economies (Fig. 7e and f).

Apart from the high correlation between model forecasts and observed data, the ranking is consistent for all cases in Fig. 7 before the 2007-2008 financial downturn. In particular the model correctly forecasts that the Chinese GDP overtook the Japanese GDP. We can then conclude that the model's validation is positive for the steady state.

\section{Propagation of Shocks in the IMM}

We have confirmed that the IMM is capable of modelling multi-layered dynamic trade interactions among countries. We aim here to apply the model to shocks and the propagation of 'events'. Our analysis seeks to identify the countries that can trigger cascading effects and evaluate their magnitude. The IMM is comprised of several interlinked sub systems which interact according to the schema presented in Fig. 4 and Section 2. Among these sub systems, we focus on the trade network in order to identify the countries that are central in the international network and most inclined to diffuse (potentially harmful) effects on the international trade system. We use the eigenvector centrality (Bonacich 2007) to measure the role of each country in propagating economic impacts on neighbouring countries. Eigenvector analysis provides a measure of the direct influence between a node and its neighbour nodes, which subsequently influences other nodes directly connected to them (who themselves influence still others). The first node is highly influential if it easily propagates 'events' 
(a)

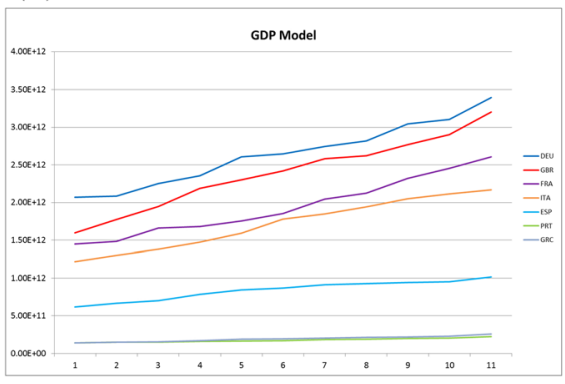

(c)

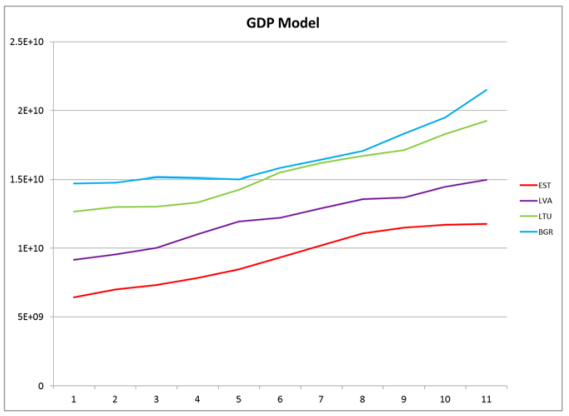

(e)

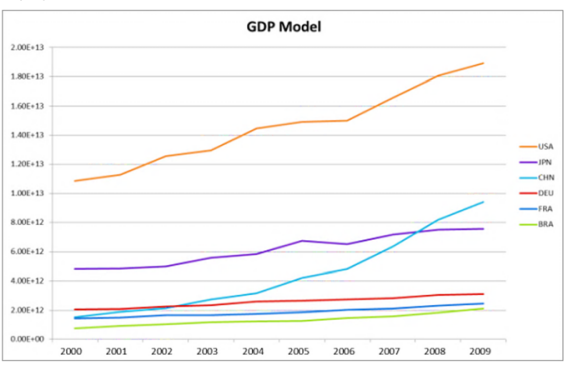

(b)

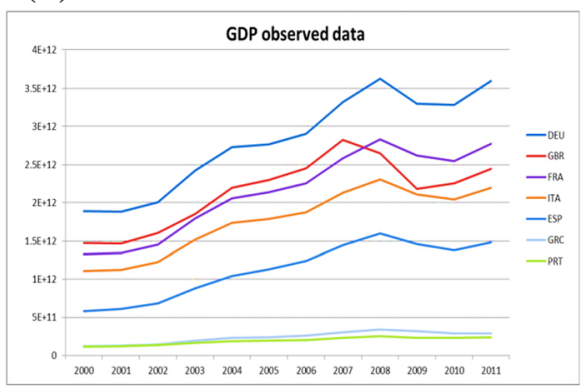

(d)

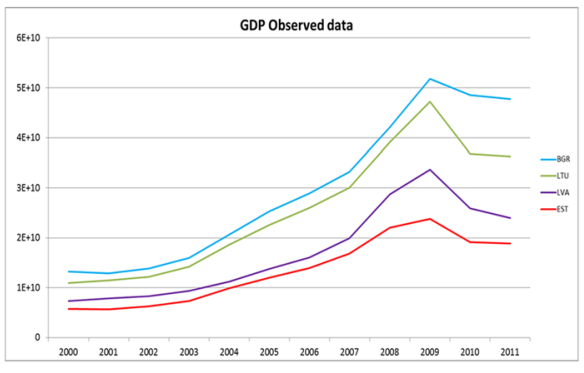

(f)

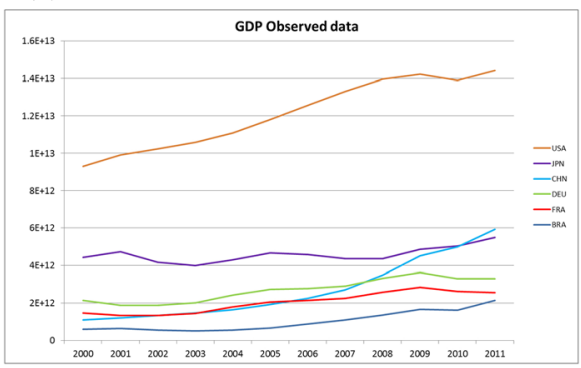

Fig. 7 IMM results for the steady state. GDP forecast versus observed data for European countries (a and b), Baltic States (c and $\mathbf{d}$ ) and six major world economies (e and $\mathbf{f}$ )

(such as an economic crisis in our case) in the network (Borgatti 2005). We perform the eigenvector analysis for the trade network for a 10-step simulation as shown in Table 6. We can observe that the ranking is consistently stable over the observation period because the model does not introduce dynamic modifications in the topology of the network (i.e. new links are not created nor are existing links removed). Hence in Table 6 we report the average value of eigenvector analysis of each country. The zone of highest importance (i.e. central in the network) is North America: the USA is twice as much important than Germany (the most central European country).

We next evaluate the magnitude of the diffusion effect on the IMM layers (vertical propagation) by introducing external shocks for two case studies: the USA, which is the country most central in the network (Fig. 8), and Germany, which is the most central European country in the network (Fig. 9). 
Table 6 Country ranking of eigenvector centrality index for the bilateral trade network: the highest is the eigenvector centrality index, the most important is a node

\begin{tabular}{|c|c|c|c|c|c|}
\hline Position & Country & Value & Position & Country & Value \\
\hline 1 & USA & 0.5723 & 21 & RUS & 0.0446 \\
\hline 2 & CAN & 0.4293 & 22 & AUT & 0.0360 \\
\hline 3 & JPN & 0.3806 & 23 & DNK & 0.0309 \\
\hline 4 & DEU & 0.2541 & 24 & FIN & 0.0211 \\
\hline 5 & $\mathrm{CHN}$ & 0.2419 & 25 & TUR & 0.0220 \\
\hline 6 & MEX & 0.2203 & 26 & POL & 0.0198 \\
\hline 7 & GBR & 0.1933 & 27 & CZE & 0.0139 \\
\hline 8 & FRA & 0.1651 & 28 & HUN & 0.0134 \\
\hline 9 & KOR & 0.1566 & 29 & PRT & 0.0122 \\
\hline 10 & TWN & 0.1466 & 30 & LUX & 0.0105 \\
\hline 11 & ITA & 0.1351 & 31 & GRC & 0.0071 \\
\hline 12 & NLD & 0.0913 & 32 & ROU & 0.0044 \\
\hline 13 & AUS & 0.0712 & 33 & SVK & 0.0041 \\
\hline 14 & BEL & 0.0694 & 34 & SVN & 0.0038 \\
\hline 15 & IRL & 0.0580 & 35 & BGR & 0.0020 \\
\hline 16 & ESP & 0.0576 & 36 & MLT & 0.0020 \\
\hline 17 & IDN & 0.0520 & 37 & EST & 0.0013 \\
\hline 18 & IND & 0.0541 & 38 & LTU & 0.0013 \\
\hline 19 & BRA & 0.0505 & 39 & LVA & 0.0011 \\
\hline 20 & SWE & 0.0521 & 40 & CYP & 0.0008 \\
\hline
\end{tabular}

In the first case, the simulated shock in the US economy is generated by introducing a decrease in the US GDP of $2 \%$ between step 6 and 9 of the simulation (Fig. 8). When we compare these results with the steady state, a few countries show a clear dependency from the US than others. This is the case of Germany, France and Japan. On the other hand, China seems to take advantage of an economic crisis in the US.

In the second test we apply a shock in the German GDP. We follow the same strategy used for the US: a decrease of GDP of $2 \%$ between step 6 and 9 (Fig. 9). Also in this case we observe that the imposed endogenous shock in one country has affected other nations, both positively and negatively. The Asian countries (Japan and China) appear to be the most affected by an internal crisis in Germany. In Europe, the economies of Germany and the UK do not appear to be very connected, as a decrease in the German GDP does not affect the UK economy. The same effect has been recorded in the first test: while the German GDP began to lessen as the US GDP decreased, the UK GDP remained unaffected. Finally, in the Baltic States, Latvia appears to be more affected by a US crisis (Fig. 8), and Estonia is impacted more by a German economic crisis (Fig. 9).

We can conclude this section by observing that the model, under the two tests, can potentially analyse shocks and their impacts. Nonetheless, we recognise the need for more extensive analyses in order to verify the robustness of the model in relation to the 
(a)

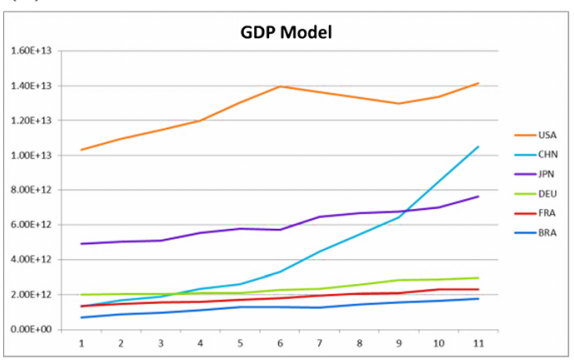

(b)

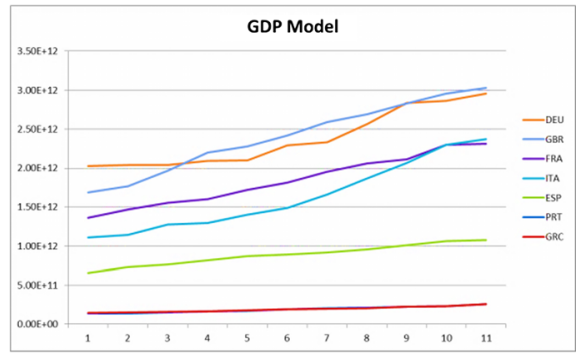

(c)

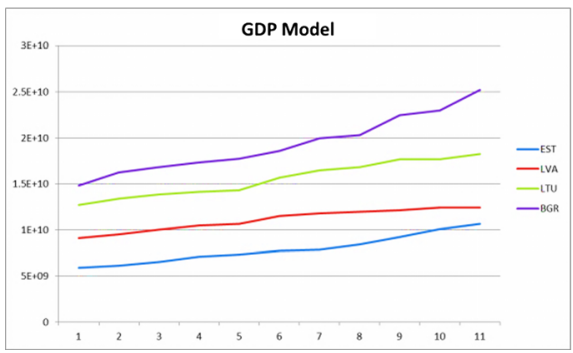

Fig. 8 Effect of $2 \%$ decrease of US GDP over 4 time steps (6 to 9) for major world economies (a), European countries $(\mathbf{b})$ and Baltic States (c)

effects of shocks to the networks. This type of analysis is, however, beyond the scope of the present work but will be the objective of our future research.

(a)

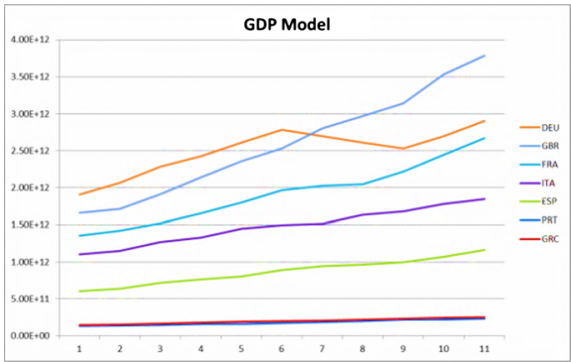

(c)

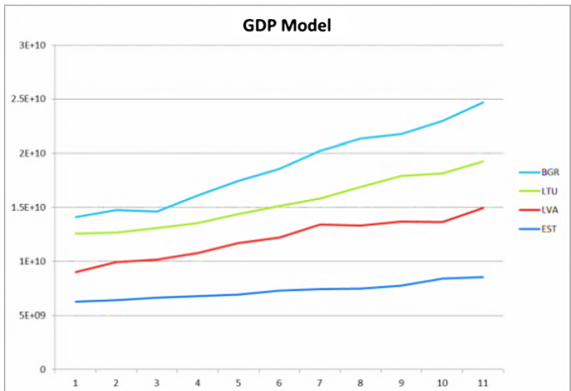

(b)

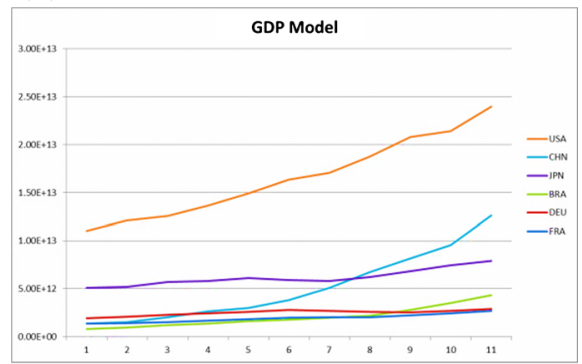

Fig. 9 Effect of $2 \%$ decrease of German GDP over 4 time steps (6 to 9) for European countries (a), major world economies (b) and Baltic States (c) 


\section{Discussion and Conclusions}

We have proposed in this paper a new model with which to analyse and examine bilateral trade. Underpinning the development of the Interdependent Multi-layer Model (IMM) we can confirm the presence of interdependence among countries and factors that determine trade, and interactions among the different elements (layers) that define the international trade system. Within each layer we have examined the horizontal connections, and between layers we have modelled the interdependent vertical connections, and in so doing we have been able to represent the inherent complexity of trade networks. The results show that, in the trade market, countries certainly interact with each other but they do not follow standard frameworks; instead, their interactions depend on their specific spatial, economic and social conditions.

We have also tested the model under potential possible shocks, such as a decrease in GDP, and we have verified that the model can satisfactorily simulate and identify scenarios of the countries after events/shocks have taken place.

The IMM can therefore be regarded as a useful tool for decision makers in the global trade market in further understanding the causality and directionality of certain parameters that influence trade. These results are interesting and powerful, particularly in light of the complexity of international trade processes and also contribute to the literature since a better understanding of the processes that influence and determine trade can not only shed light on how countries can grow through trade, but can also help in the design of policies for sustainable economic growth.

Acknowledgments The authors acknowledge the financial support of the Engineering and Physical Sciences Research Council (EPSRC) under the grant ENFOLD-ing: Explaining, Modelling and Forecasting Global Dynamics, reference EP/H02185X/1.

Open Access This article is distributed under the terms of the Creative Commons Attribution License which permits any use, distribution, and reproduction in any medium, provided the original author(s) and the source are credited.

\section{References}

Aashtiani HZ, Magnanti TL (1981) Equilibria on a congested transportation network. SIAM J Algebraic Discret Meth 2(3):213-226

Abel GJ, Bijak J, Findlay AM, McCollum D, Wiśniowski A (2013) Forecasting environmental migration to the United Kingdom: an exploration using Bayesian models. Popul Environ 35(2): 183-203

Abel GJ (2013) Estimating global migration flow tables using place of birth data. Demogr Res 28(18):505546

Akhtar R, Santos JR (2013) Risk-based input-output analysis of hurricane impacts on interdependent regional workforce systems. Nat Hazards 65(1):391-405

Anderson JE, Van Wincoop E (2004) Trade costs. National Bureau of Economic Research, No. w10480

Bade R, Parkin M (2007) Foundations of economics. Pearson Addison Wesley, New Jersey

Baldwin R, Taglioni D (2006) Gravity for dummies and dummies for gravity equation. NBER working paper no. 12516, National Bureau of Economic Research, Inc

Barbieri K, Keshk OMG (2012) Correlates of War Project Trade Data Set Codebook. Version 3.0. Online: http://correlatesofwar.org

Barbieri K, Keshk OMG, Pollins B (2009) TRADING DATA: evaluating our assumptions and coding rules. Conflict Manag Peace Sci 26(5):471-491 
Barrat A, Barthelemy M, Pastor-Satorras R, Vespignani A (2004) The architecture of complex weighted networks. PNAS 101:3747-3752

Bergstrand JH (1985) The gravity equation in international trade: some microeconomic foundations and empirical evidence. Rev Econ Stat 67(3):474-481

Bonacich P (2007) Some unique properties of eigenvector centrality. Soc Networks 29:555-564

Borgatti SP (2005) Centrality and network flow. Soc Networks 27(1):55-71

Buldyrev S, Parshani R, Paul G, Stanley HE, Havlin S (2010) Catastrophic cascade of failures in interdependent networks. Nature 464:1025-1028

Burger MJ, Van der Knaap B, Wall RS (2014) Polycentricity and the multiplexity of urban networks. Eur Plan Stud 22(4):816-840

Burns WJ, Slovic P (2012) Risk perception and behaviors: anticipating and responding to crises. Risk Anal 32: 579-582

Büthe T, Milner HV (2008) The politics of Foreign Direct Investment in developing Countries: increasing FDI through international trade agreements. Am J Polit Sci 52:741-762

Caschili S, Medda F, Parola F, Ferrari C (2014) An analysis of shipping agreements: the cooperative container network. Netw Spat Econ. doi:10.1007/s11067-014-9230-1

Castet JF, Saleh JH (2013) Interdependent multi-layer networks: modeling and survivability analysis with applications to space-based networks. PLoS One 8(4):e60402

Clauset A, Moore C, Newman ME (2008) Hierarchical structure and the prediction of missing links in networks. Nature 453(7191):98-101

Deardorff A (1998) Determinants of bilateral trade: does gravity work in a neoclassical world? In: The regionalization of the world economy, 7-32, University of Chicago Press

Ducruet C, Beauguitte L (2013) Spatial science and network science: review and outcomes of a complex relationship. Netw Spat Econ. doi:10.1007/s11067-013-9222-6

Duval R, Elmeskov J, Vogel L (2007) Structural policies and economic resilience to shocks. OECD Economics Department Working Papers No. 567

Gao J, Buldyrev SV, Havlin S, Stanley HE (2011) Robustness of a network of networks. Phys Rev Lett 107: 195701

Garelli S (2003) Competitiveness of nations: the fundamentals. IMD World competitiveness yearbook

Glick R, Rose A (2002) Does a currency union affect trade? The time series evidence. Eur Econ Rev 46(6): 1125-1151

Gunasekaran A, Patel C, Tirtiroglu E (2001) Performance measures and metrics in a supply chain environment. Int J Oper Prod Manag 21(1-2):71-87

Harvie C (2004) East Asian SME capacity building, competitiveness and market opportunities in a global economy. Faculty of Commerce-Economics Working Papers, 100

Head K, Mayer T, Ries J (2010) The erosion of colonial trade linkages after independence. J Int Econ 81(1):1-14

Helpman H (2011) Understanding global trade. Harvard University Press, London

Hill EW, Wial H, Wolman H (2008) Exploring regional economic resilience. Working Paper 2008-04, Institute of Urban and Regional Development, University of California, Berkeley

Holling CS (1973) Resilience and stability of ecological systems. Annu Rev Ecol Syst 4:1-23

Holt RPF, Barkley JR Jr, Colander D (2011) The complexity era in economics. Rev Polit Econ 23(3):357-369

Hufbauer G (1970) The impact of national characteristics and technology on the commodity composition of trade in manufactured goods. In: The technology factor in international trade. 143-232, UMI

Hummels D (1999) Towards a geography of trade costs. University of Chicago. Mimeographed document

Immaculada MZ, Celestino SB (2005) Transport costs and trade: empirical evidence for Latin American imports from the European Union. J Int Trade Econ Dev Int Comp Rev 14(3):353-371

International Monetary Fund (2012) Direction of trade statistics yearbook. Washington DC (USA)

Kuznets S (1946) National income: a summary of findings. National Bureau of Economic Research, New York

Levin S, Barrett S, Aniyar S, Baumol W, Bliss C, Bolin B (1998) Resilience in natural and socio-economic systems. Environ Dev Econ 3(2):222-234

Limao N, Venables AJ (2001) Infrastructure, geographical disadvantage, transport costs and trade. World Bank Econ Rev 15:451-479

Linders GJM, Slangen A, de Groot HLF, Beugelsdijk S (2005) Cultural and institutional determinants of bilateral trade flows. Tinbergen Institute Discussion Paper No. 2005-074/3

Linneman H (1966) An economic study of international trade flows. North-Holland, Amsterdam

Liu J, Dietz T, Carpenter S, Alberti M, Folke M et al (2007) Complexity of coupled human and natural systems. Science 317(5844):1513-1516 
Marincioni F, Appiotti F, Pusceddu A, Byrne K (2013) Enhancing resistance and resilience to disasters with microfinance: parallels with ecological trophic systems. Int J Disaster Risk Reduction 4:52-62

Markose SM (2005) Computability and evolutionary complexity: markets as Complex Adaptive Systems (CAS). Econ J 115:F159-F192

Martin RL (2012) Regional economic resilience, hysteresis and recessionary shocks. J Econ Geogr 12:1-32

Matsziw TC, Murray AT, Grubesic TH (2009) Strategic network restoration. Netw Spat Econ 10:345-361

Matyas L (1997) Proper econometric specification of the Gravity Model. World Econ 20(3):363-368

Mayer T, Zignago S (2011) Notes on CEPII's distance measures (GeoDist). CEPII Working Paper 2011-2025

McCallum J (1995) National borders matter: Canada-US regional trade patterns. Am Econ Rev 85(3):615-623

Muchnik L, Pei S, Parra LC, Reis SD, Andrade JS Jr, Havlin S, Makse HA (2013) Origins of power-law degree distribution in the heterogeneity of human activity in social networks. Sci Rep, 3

Newman ME (2003) The structure and function of complex networks. SIAM Rev 45(2):167-256

O'Kelly M (2010) Routing traffic at hub facilities. Netw Spat Econ 10(2):173-191

OECD (2009) National Accounts of OECD Countries 2009, -Volume I, Main Aggregates, OECD Publishing

Parshani R, Buldyrev SV, Havlin SH (2010) Interdependent networks: reducing the coupling strength leads to a change from a first to second order percolation transition. Phys Rev Lett 105:048701

Pastor-Satorras R, Vespignani A (2001) Epidemic spreading in scale-free networks. Phys Rev Lett 86(14): 3200-3203

Pimm SL (1984) The complexity and stability of ecosystems. Nature 307:321-326

Pullianen P (1963) World trade study: an economic model of the pattern of the commodity flows in international trade 1948-1960. Ekon Samfundets 2:78-91

Rauch JE (1999) Networks versus markets in international trade. J Int Econ 48:7-35

Reggiani A, De Graaff T, Nijkamp P (2002) Resilience: an evolutionary approach to spatial economic systems. Netw Spat Econ 2(2):211-229

Rinaldi SM, Peerenboom JP, Kelly TK (2001) Identifying, understanding and analyzing critical infrastructure interdependencies. Control Syst IEEE 21(6):11-25

Rose AZ (2007) Economic resilience to natural and man-made disasters: multidisciplinary origins and contextual dimensions. Environ Hazards 7:383-398

Rosser JB (1999) On the complexities of complex economic dynamics. J Econ Perspect 13(4):169-192

Shahabi M, Akbarinasaji S, Unnikrishnan A, James R (2013) Integrated inventory control and facility location decisions in a multi-echelon supply chain network with hubs. Netw Spat Econ 13(4):497-514

Strogatz SH (2001) Exploring complex networks. Nature 410(6825):268-276

Tang CS (2006) Robust strategies for mitigating supply chain disruptions. Int J Logist Res Appl 9(1):33-45

Teng SG, Jaramillo H (2005) A model for evaluation and selection of suppliers in global textile and apparel supply chains. Int J Phys Distrib Logist Manag 35(7):503-523

Tinbergen J (1962) Shaping the world economy: suggestions for an international economic policy. Twentieth Century Fund, New York

Wilson AG (1967) A statistical theory of spatial distribution models. Transp Res 1:253-269

Wilson AG (1970) Entropy in urban and regional models. Pion, London

Wilson AG (1971) A family of spatial interaction models and associated developments. Environ Plan 3:1-32

Yue C, Beghin J, Jensen HH (2006) Tariff equivalent of technical barriers to trade with imperfect substitution and trade costs. Am J Agric Econ 88(4):947-960 